\title{
Multisensory Inclusive Design Education: A 3D Experience
}

\section{Burçak Altay}

To cite this article: Burçak Altay (2017) Multisensory Inclusive Design Education: A 3D Experience, The Design Journal, 20:6, 821-846, DOI: 10.1080/14606925.2017.1371949

To link to this article: https://doi.org/10.1080/14606925.2017.1371949

曲 Published online: 19 Sep 2017.

Submit your article to this journal ¿

Џ Article views: 159

Q View related articles $\sqsubset$

View Crossmark data $\gtrsim$ 


\title{
Multisensory Inclusive Design Education: A 3D Experience
}

\author{
Burçak Altay \\ Bilkent University, Ankara, Turkey
}

ABSTRACT Inclusive design should be an integral part of the curriculum in the education of environmental design disciplines, incorporating empathic understanding. Among the empathic methods that are employed, 'build-to-learn' that promotes experiential learning is effective in students' multisensory and bodily engagement with the process and product. This paper discusses an exercise in a Human Factors/ Ergonomics course in interior design where students create 'A 3D Experience'. Analysis of exemplary work suggests various ways in which different senses may come forth into awareness to sometimes enrich and at other times limit embodied space, thus opening up a venue of inclusivity in novel and unpredictable ways. Research conducted on student perspectives reveals that the assignment had positive impact on their understanding and awareness of, and attitudes towards, inclusive design, as well as creative thinking.

KEYWORDS: inclusive design, design education, multisensory design, ergonomics, design and empathy 


\section{Introduction}

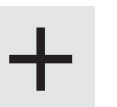

In order to accommodate the match between different needs of people and the environment - the person-environment fit

- designers should take into account the diversity of people during design process. Appreciating human diversity in all its aspects ranging from age, sex, socio-economic conditions, and different abilities to emotions, feelings, and psychological requirements can increase the quality of user-centred design. This calls for an empathic design approach.

Empathic understanding refers to stepping away from a designer role to identify with the actual users who will engage with the designed product/environment (Kouprie and Visser 2009). This necessitates being immersed in the lives, experiences, and ways-of-living of populations with varying physical characteristics and capabilities. Empathy involves relating to, more than just knowing about the user (Kouprie and Visser 2009). Empathic design is particularly important where the designers have the opportunity to create design solutions for people who have different abilities than their own, whom they can encourage to live high-quality, empowered, and independent lives - such as older adults and those with certain capability losses (McDonagh and Thomas 2010).

Recognizing empathy as a powerful tool to expand the depth, scope, and implementation of ergonomics discipline, Suri suggests:

Ergonomics information can be vivid and engaging when it resonates with other people's experiences. If we devise ways of helping planners and implementers to empathize with the people who will be affected by their decisions, we create more fertile ground for ergonomics recommendations and broader support for resolving critical issues. (Suri 2001, 1286)

The application of inclusive design and ergonomics information by design practitioners, however, has been troublesome (McGinley and Dong 2011; Nickpour and Dong 2011). As research shows, design practitioners mainly use tacit sources, including their own acquired experience, intuition, and common sense. They also interact with the users when possible and apply prototyping and model-making, finding them more useful than written and computer-based sources and tools of anthropometric data (Nickpour and Dong 2011). At this point, the mindset and attitudes of designers towards inclusivity has to be established (Postma et al. 2012). The educational environment can be a fertile and promising ground to initiate and develop attitudes of future designers for inclusivity, and to seek possible strategies that encourage them to apply information with an enhanced empathic understanding towards users.

\section{Inclusive Design Education}

Morrow states that the design education curriculum should embrace an inclusive design approach in a multitude of dimensions within courses 
at different levels (2002). In education, the major objective in the affective learning domain should be to establish a value system regarding the responsibilities of designers in order to create user-friendly environments. However, initially, the novice design students' work is guided - but also limited - by their understanding of the 'user' based on previous knowledge, observation, and experience (McDonagh and Thomas 2010). Moreover, user representations of designers during the design process in the absence of users, created by scenarios and personas, have a danger of creating stereotypes, with the exclusion of certain user groups (Turner and Turner 2011). The underlying beliefs and stereotypical attitudes of exclusion need to be challenged and altered to provide long-term consequences and change (Wijk 2001). Students' ethical position and attitudes towards diverse users will in turn have a direct impact on the way they design products/spaces. At this point, the more we move beyond categorizations of 'user', 'student', 'instructor', 'architect', and 'designer', with increasing transparency and transfusion of these roles, the more integrative environments we are to create.

In user-centred design education, indirect data from research may be obtained through communication of user studies, research findings, and photographic and verbal documentation (Kouprie and Visser 2009). Direct information can be obtained from interviewing and participant observation, shadowing, and simulation/empathic modelling (Altay and Demirkan 2014; Cardoso and Clarkson 2012; McDonagh and Thomas 2010). In empathic modelling, the designer may simulate a specific interaction with a product/space and relate to experiences different from her everyday relationship.

Considering the effectiveness of simulation methods, the literature contains both critical (French 1992; Hitchcock and Taylor 2003) and positive evaluations and applications (Nicolle and Maguire 2003; Peel and Posas 2009). Burgstahler and Doe (2004) provide guidelines for effective simulations. Primarily, a thorough briefing is required, emphasizing the difference of the simulation experience from that of disabled people, who have distinct coping strategies and acquired skills due to their longitudinal experience. A clear statement of objectives, promotion of positive attitude change, and focus on the importance of inclusive design are also suggested. Indeed, simulation methods emphasizing inclusive design have demonstrated that students expanded their learning in both cognitive and affective domains with observed sensitivity towards inclusive design (Altay and Demirkan 2014).

\section{Multisensory Design}

The structuring of inclusive design education need not necessarily be that of the differences between designers and others, but an expansion of the understanding and awareness of one's own capabilities. As such, through the realization of the degree of ability of one or more of the senses, an alteration of the designer's interaction with a product/space in different sensory modalities may provide an opportunity for him to reflect on the experience and widen his point of view. This 
may allow the student to integrate the acquired sensory domains into design and create solutions that are not only innovative, but that also resonate with other users' capabilities.

Every individual's capabilities when interacting with products and spaces differ in range and degree. Thus, a person may have full ability, moderate ability, partial ability, and minimal or inability, which may reduce or prevent the appropriate use of certain products/spaces (Clarkson 2008). These capabilities include sensory, motor, and cognitive domains. The visual, tactile, auditory, olfactory, and tasting domains constitute the sensory domain. Motor capabilities comprise locomotion (walking and balance, getting up/down/in/out, etc.), reaching and stretching, and dexterity. Cognitive capabilities, on the other hand, include intellectual functioning and communication.

In the environmental design disciplines, particularly visual tools are utilized during education as well as practice (Elsen and Heylighen 2014). Although the visual focus in architectural education is identified as a strength of design thinking (Cross 1982) and designerly ways of knowing, it has also been argued to create some hindrances in acknowledging the spatial experience by other senses (Wastiels et al. 2013). For example, in assessing materials of buildings, different attributes have been associated with materials when students made purely tactile evaluations, purely visual evaluations, or both (Wastiels et al. 2013), which suggests that all of the senses should be incorporated into the design process for accurate and thorough evaluations. Similarly, in product design, designers are suggested to sensitize with sensory modalities other than the dominant visual sense during exercises that explore the environment's tactual and auditory properties (Schifferstein and Desmet 2008).

Schifferstein and Spence (2008) discuss products from a multisensory perspective that captures the complexity of the user experience. When encountering products, the degree to which one sensory modality is dominantly used, whether other senses come forth with the blocking of one sense, how the utilization of multiple senses influence one another, as well as the total experience, are all aspects that are crucial in understanding the interaction. Moreover, the product congruence with the users' sensory and motor capabilities, as well as user intentions, has an effect on their emotional responses (Schifferstein and Desmet 2008). In that respect, the experiential component has a close link with the affective component, resulting in user satisfaction or dissatisfaction due to the capabilities the interaction can embrace. Therefore, incorporation of ergonomics knowledge related to anthropometric data, as well as the range of user responses to sensory stimuli, is essential to create environments that afford sensory, motor, and cognitive capabilities.

\section{Experiential Learning/Build-to-Learn}

Regarding inclusivity, Nicolle and Maguire (2003) indicate the necessity for learning environments that offer students the opportunity to 
translate what they have learned into actual design outcomes. Thus, applying principles into practice is a significant component of learning. Project-based learning, and particularly build-to-learn, is an appropriate venue for such a process. Here, students create their own solutions as a final outcome to a given problem. The problem with a possibility of numerous solutions is redefined, interpreted, and developed during the process (Aditomo et al. 2011; Lee 2009).

Grounded in the appreciation of concrete experience and active experimentation in the experiential learning cycle modelled by Kolb (1984), build-to-learn as a form of pedagogical practice is utilized in interior design education. Konkel (2014) reports that the build-to-learn approach is predominantly applied in the studio course, but extends to courses on materials and methods, furniture design, and construction detailing. Instructors state the positive learning outcomes as an improved understanding of materiality, creative design solutions, and an increased enthusiasm for the course material. Moreover, Charlesworth (2007) compares the use of virtual modelling versus physical modelling during a design development phase for a product design. The study reveals that when students actually interact with the material and make models, this reflects back to the design development and opens venues for further decision-making. However, virtual modelling is mainly used for presentation purposes, after the design development phase is largely completed. Thus, the sensory experience provided during the model-making process allows creative ideas to flourish and mature. Similarly, Elsen and Heylighen (2014) suggest that prototyping and usage of actual models are successful to better understand user interaction with the product/environment in professional practice.

Despite the difficulty in applicability, real models that connect the users to space in full scale rather than representational models of smaller scales are more beneficial (Konkel 2014). While they enhance engagement with the materials and construction, students also gain insight about the spatial experience by all the senses (Altay et al. 2016). Thus, build-to-learn models not only embody the advantage of simulation methods, but also go beyond that, since their objective is to place one's own self at the centre of the experience. The shift of focus is away from the capabilities of people with disabilities, as French (1992) rightly cautioned, and towards the physical environment and social system which could/should be altered to allow for an overarching inclusion. The following section discusses an assignment where build-to-learn is used as a pedagogical tool in a Human Factors/Ergonomics course for second-year interior design students.

\section{A 3D Experience: Educational Context}

In the Interior Architecture and Environmental Design Department of Bilkent University, Ankara, Human Factors/Ergonomics (HFE) is a second-year, single-semester course. The course contents include the principle and practice of anthropometrics and universal design, with focus lectures on specific design problems within public spaces 
and office and home environments. The expected learning outcomes related to the cognitive domain are: increased understanding and awareness of inclusivity and HFE knowledge as well as analysis, evaluation, and creation of products/spaces according to HFE criteria. The learning outcomes related to the affective domain are: formation and development of values that encompass acceptance, concern, attention, and taking responsibility for diverse characteristics of users, thus a valuation for inclusive design.

Within the course, active learning strategies and learner-centred methods are incorporated that focus on different user groups and apply different empathic methods. At the beginning of the course, simulation methods are applied where students explore the campus using wheelchairs, crutches, or blindfolds (Altay and Demirkan 2014). Additionally, during the second half of the course, students investigate their grandparents' experiences of their homes by collecting data through interviews and photographs (Altay 2017). Moreover, independent from the course but as an integral part of an inclusive design conference/ workshop at another university, the workshop 'A 3D Experience' was carried out with the participation of architecture and interior design students. The process, student works, and feedback yielded very positive results (Altay et al. 2016). The success of this workshop thus led to the incorporation of a similar assignment to the syllabus of the HFE course.

Within this framework, we introduced 'A 3D Experience to Increase Inclusive Design Awareness', exploring the following issues:

- How does the interaction occur between the spaces/products/elements that we design, and those of people with different physical characteristics, needs, requirements, expectations?

- What type of spaces/products reveal qualities in us that we are more ourselves, rather than less; integrate rather than separate; enable rather than disable?

- How can we provide a different understanding of our own relationship to spaces/products through design?

- How can we empathize with others by embodying their experiences through our own sensory knowledge?

The students were expected to explore and construct their own knowledge in relation to space - therefore, connect with their own bodies and senses. They would also find the opportunity to relate to others in the process. It was clarified to the students that the end product should not be a representation of a certain spatial experience, but rather an end in itself. Utilization of HFE knowledge and data was encouraged. The only limitation was that the extent of the work should not exceed $2 \mathrm{~m}$ in any direction. They also submitted a poster explaining the design idea and project intentions.

Within a three-week duration, the students voluntarily formed groups of three-four and spent off-class hours to develop their project. During this time, they received one critique from the instructor on their initial ideas and intentions of production, suggestions for material use, 
etc. After production, projects were brought to the classroom/department halls. A 90-minute session was devoted to the experience of the works while all the students briefly explained their ideas. Students had a chance to vote for their favourite project, in writing, which was later announced. The works were exhibited in the department halls for other colleagues and students to engage with.

The major consideration for project evaluation was the potential of the $3 \mathrm{D}$ experience to increase awareness of our relationship with the environment. Thus, original experiences, particularly those through which we learned more about our encounter with the environment, ranked high in assessment. Creativity and the focus of the project was observed. Moreover, the works were considered in terms of design unity, structural stability, and workmanship. The project constituted $10 \%$ of overall grading. In the three consecutive terms in 2014-2015, students created approximately 60 projects.

\section{Assessment of Effectiveness of the Assignment}

In order to evaluate the effectiveness of teaching and learning, both direct and indirect methods can be utilized. Direct methods include student academic work, such as student performances, creations, reports, standardized tests, portfolios, etc. Indirect methods include students' perceptions of learning through focus groups, interviews, surveys, and questionnaires (Maki 2004; National Research Council 2003). Researchers suggest multiple sources rather than a single source to understand the multidimensional nature of learning. Indirect methods can contribute to the results gained from direct methods of learning, and help deepening understanding of student growth (Bowman and Herzog 2011). In addition to students' perceptions of teaching, they also indicate how they experience the learning process (Theall and Feldman 2007).

In instructional literature, we see studies that utilize complementary methods including both the material obtained from the course assignments and feedback gained from students. The course material may include student diaries (Deeley 2010), submissions of the assigned tasks, teachers' own personal reflections (Cavanagh 2011), observation, or a combination of these (Lizzio and Wilson 2004; Stein, Isaacs, and Andrews 2006). Meanwhile, assessment of student perceptions about their learning may include pre-post tests, surveys conducted anonymously upon the finalization of a task or learning module (Cavanagh 2011), and in-depth reflections through semi-structured interviews and focus groups of small sample sizes (Deeley 2010). With the insights obtained from each method, the aim is to provide a comprehensive overview of the object of study from a variety of perspectives.

The first part of the current study is a direct method consisting of an analysis and presentation of sample student works. This is supported by the indirect method exploring students' perceived learning via a study conducted with students. 
Table 1. Student projects according to their sensory and bodily focus.

\begin{tabular}{ccccccc}
\hline & & & & & Bodily \\
& Project Name & & Sensory & Focus & Focus \\
\hline & & Tactile & Visual & Auditory & Olfactory & \\
1 & Crawl Space & $\checkmark$ & $\checkmark$ & & whole body \\
2 & Feel It & $\checkmark$ & $\checkmark$ & & whole body \\
3 & Cubicle of & $\checkmark$ & $\checkmark$ & $\checkmark$ & $\checkmark$ & whole body \\
& Senses & & & & whole body \\
4 & The Web & & $\checkmark$ & & hand, arm \\
5 & Black Box & $\checkmark$ & $\checkmark$ & & hand, arm \\
6 & Shape Puzzle & $\checkmark$ & $\checkmark$ & & fingers \\
7 & Smart Finger & $\checkmark$ & & & feet \\
8 & Under your Feet & $\checkmark$ & & & hand \\
9 & Touch and Draw & $\checkmark$ & $\checkmark$ & & whole body \\
10 & Dance Away & & & $\checkmark$ & fingers, \\
11 & Sound Labyrinth & & & $\checkmark$ & hand \\
& & & & & head \\
12 & Sense-Mask & $\checkmark$ & $\checkmark$ & $\checkmark$ & head \\
13 & The Pyramid & & $\checkmark$ & & head \\
14 & Inception & & $\checkmark$ & &
\end{tabular}

Among the three semesters, a selected range of projects are explored in the following section with respect to their focus on different bodily/sensory experiences. The majority of these were among those voted 'favourite' by students and were assessed with high grades. The analysis is based on the instructors' own and students' experiences and observations, in addition to students' written descriptions of the project design idea in the posters. They are also visually presented here as samples to show the range and the variety of work.

\section{Analysis of Student Works}

The sample projects are categorized according to their bodily and sensory focus (see Table 1). While some considered one sense in the absence of another (e.g. touching without seeing), others considered experiences that included many senses. Some projects were installations experienced from within, whereas others were smaller in scale, particularly designed for a body part, such as head, arm, etc. Many projects also considered problems of accessibility as an able-bodied user with different anthropometric characteristics (e.g. arm length, height, vertical grip reach, etc.).

\section{Whole-Body Movement Within Space}

Some students created three-dimensional spaces that the user could experience from within. This allowed the movement of the whole body 

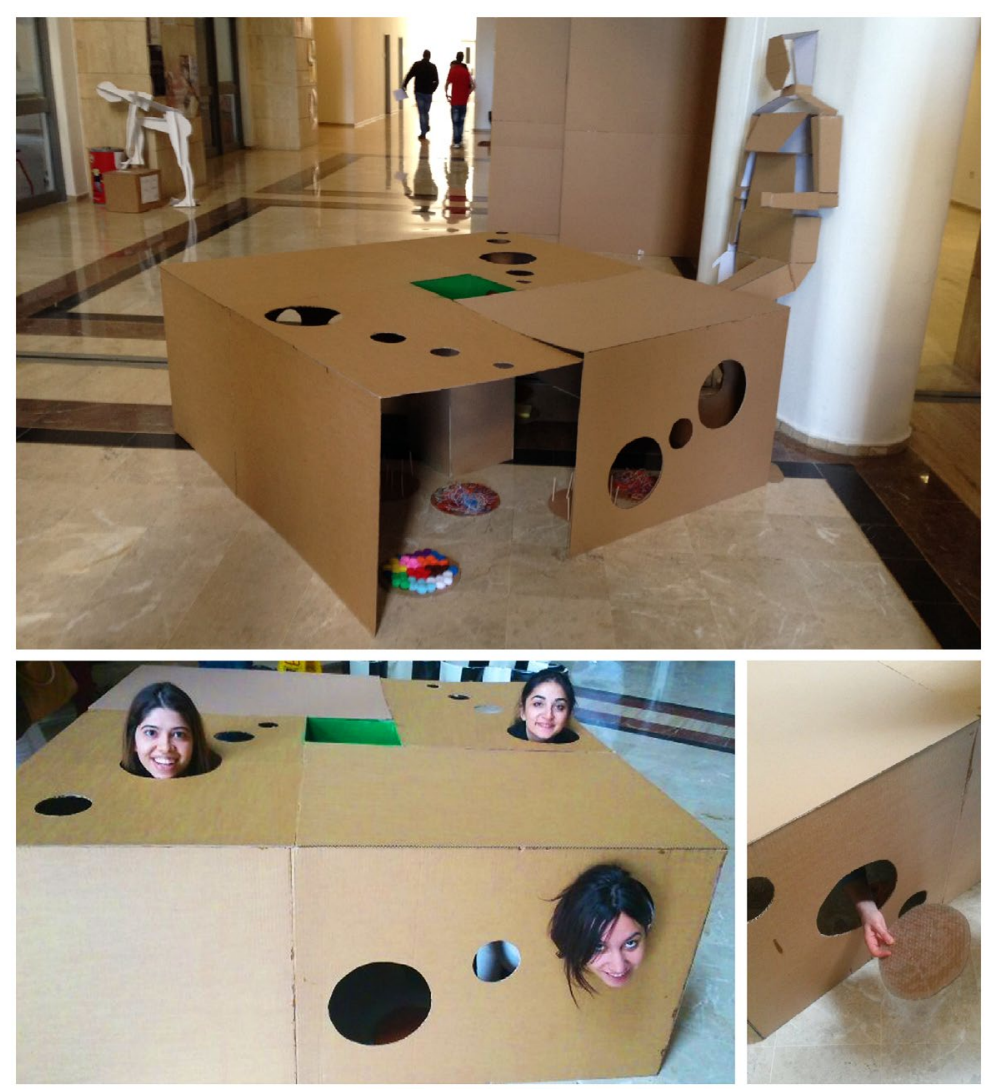

within the created environment, where a sequential experiential learning with different senses took place.

The project Crawl Space allowed exploration of a shallow space through crawling, while different floor textures were sensed through touch, and openings with different-diameter circles permitted a physical/visual relationship to the exterior (see Figure 1). Meanwhile, the green coloured centre could be accessed only by the head at the end of the journey. In Crawl Space, an interesting unpredictable bodily experience was related to the actual differences of looking through the openings. While they allowed different framings of the exterior due to their orientation, location, and size, which could be predicted, the ones closer to the ground were very limiting to the body. As we bent lower, not only was the body more restricted, but also the blood flush to the head meant that we could not look from those openings for a long time and forced us to go back to our original position.

The project Feel It invited us to empathize with other able-bodied users having different anthropometric characteristics (see Figure 2). The interactive environment allowed us to post the location of our own stature, which also marked the location from which we had to bend in order to move onward. The journey continued with obstacles that we were required to jump over, and the passageway getting narrower

\section{Figure 1.}

Crawl Space: our movement is restricted by crawling, with different views from openings and tactile effects where our hands touch. 


\section{Figure 2.}

Feel It: we become aware of our own and others' bodily dimensions that restrict movement, arriving at a natural subspace composed of leaves.
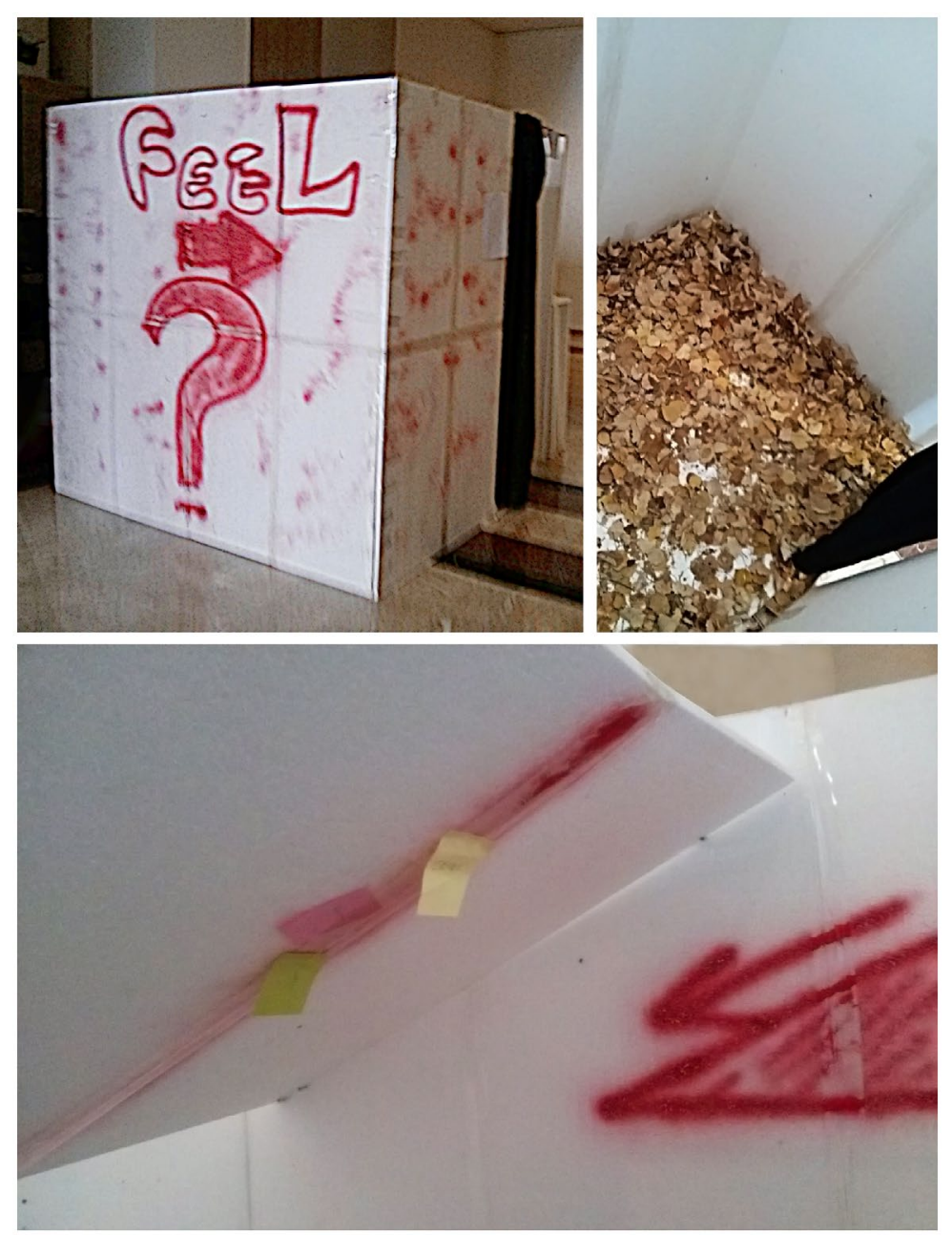

where we were forced to turn crabwise to move on. The path of obstacles ended with a tranquil space, though, of nature - symbolized by an enclosed area with leaves on the floor (originally intended to actually surround the user on the walls and ceilings) which we engaged with using multiple senses of touching, hearing, and seeing.

Another project that had subspaces with limited access for diverse users was Cubicle of Senses. The subspaces could be distinguished by their heights, widths, and degree of dark/light, bringing awareness of how our environments are mostly selectively inclusive, never experienced equally by all. It also contained surprise features. While one subspace included a fan, thus changing the air quality and an added smell of perfume, another had a view to the top, only explored upon entering (see Figure 3). Finally, when we were invited to place our hands/arms into an opening behind which we could not see, we were shocked (and thus added an auditory effect of a scream) by someone 


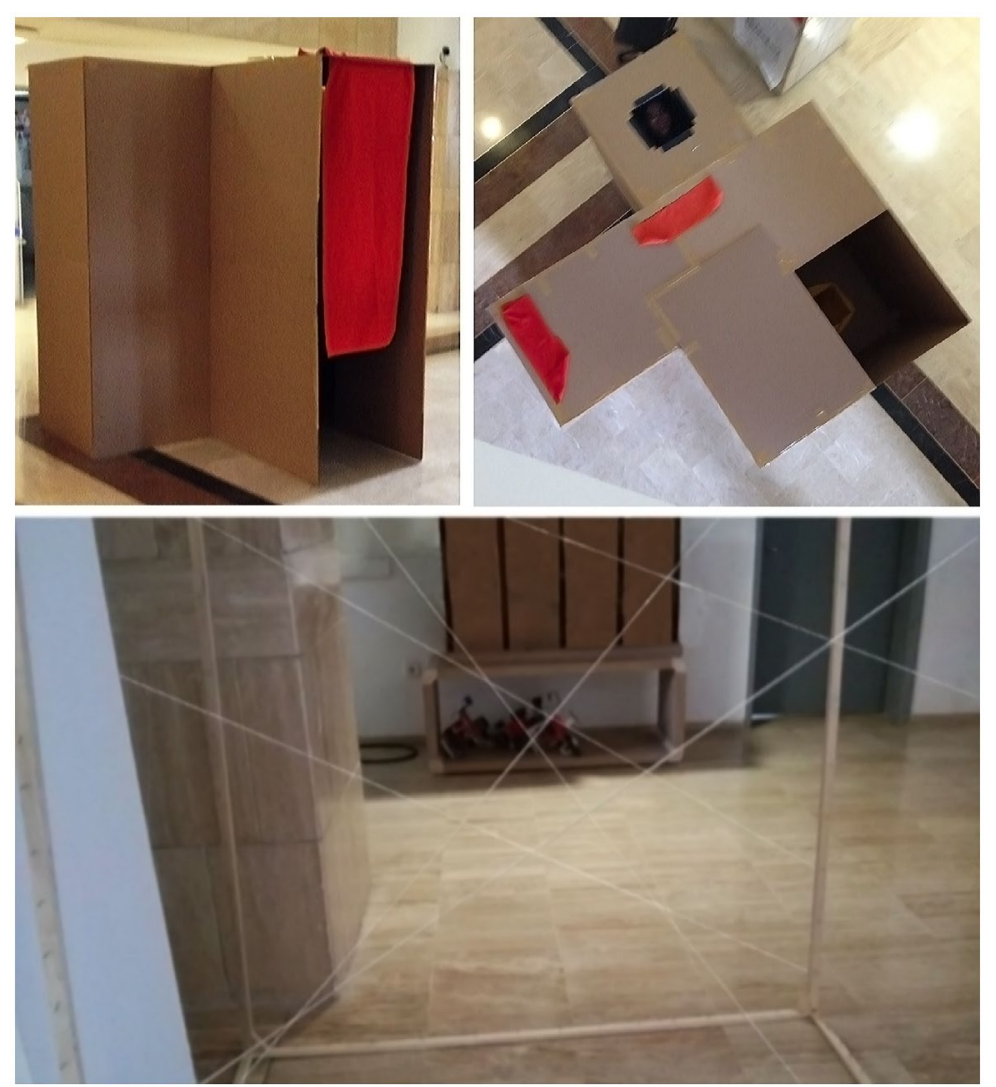

grabbing our hand from within - a student hiding and waiting to provide this effect!

A project testing the capabilities of vision and bodily movement was The Web, composed of strings attached to different corners of a cube frame of $2 \times 2 \mathrm{~m}$, creating a three-dimensional web (see Figure 3 ). We were required to pass from one corner to the other, but were challenged by not being able to see some of the strings, and had difficulty in manoeuvring our bodies to pass through allowances. Bending, hopping, and creative movement of our heads, arms, and legs were required to complete the task.

Through all of the work above, as able-bodied users, we were more attuned to coordination of our bodily parts to carry out various tasks in space, whereby we reflected on other people's experiences as they were similar to or different from ours.

\section{Tactile Focus}

While the sense of touch was encouraged in many projects, some of them exclusively focused on this, with or without sight. Black Box incorporated textures within a tunnel surrounding the arm (see Figure 4). However, the textures terminated and changed at the intervals marking

\section{Figure 3.}

Cubicle of Senses: we have a multisensory spatial experience. The Web: we conduct different bodily movements to see the strings and pass through. 


\section{Figure 4.}

Black Box and Shape Match: we explore the capabilities and limits of arm reach for different tactile and formal properties of materials.

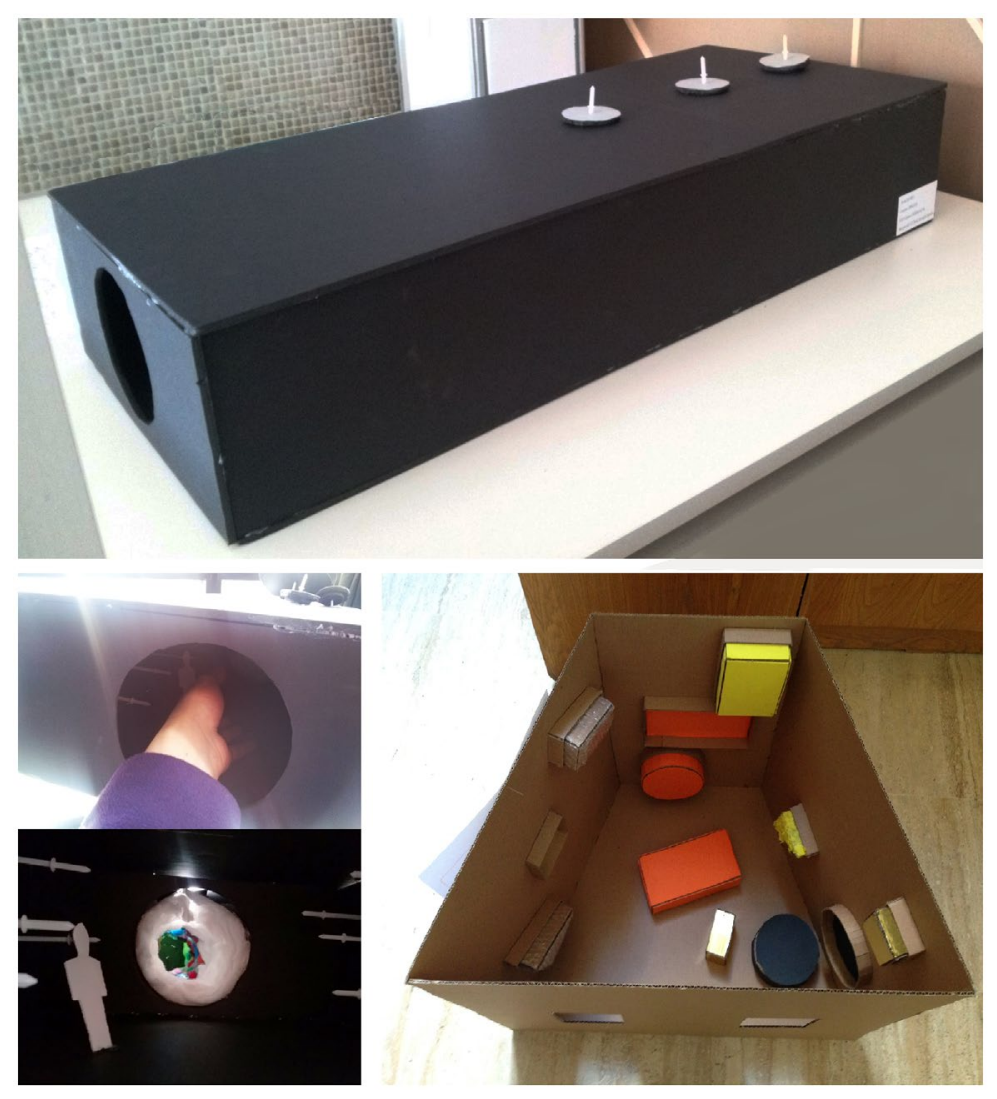

the arm length of 5th percentile female, 5th percentile male, 95th percentile female, and 95th percentile male, which provided accessibility of all the textures only to a limited group of the population. As such, the work increased our understanding that even such a simple task could be experienced differently by various groups. This project also encouraged a different point of view; with the inclusion of a scaled human figure at the tunnel, the viewer could imagine herself walking in the tunnel of textures with changing light, shade, and shadow effects from the openings.

In Shape Match, the blindfolded user had to match the objects with locations of identical shape and texture across the inner surface of the box, via guessing them without sight (see Figure 4). This project also focused on arm reach, since users without sight had difficulty in reaching the locations at the far corners of the inner surface of the box.

Focusing on a different body part, Smart Finger invited us to find the end of the labyrinth with eyes closed, while our finger followed the cues provided by the tactile properties of the ground and the walls (see Figure 5). Textured signs on the ground directed us to go forward, turn left or right, soft textures assured us we were on the right track, and spiky textures warned us. Meanwhile, Under Your Feet encouraged us to feel the sensations - sometimes soft, and at other times disturbing - 

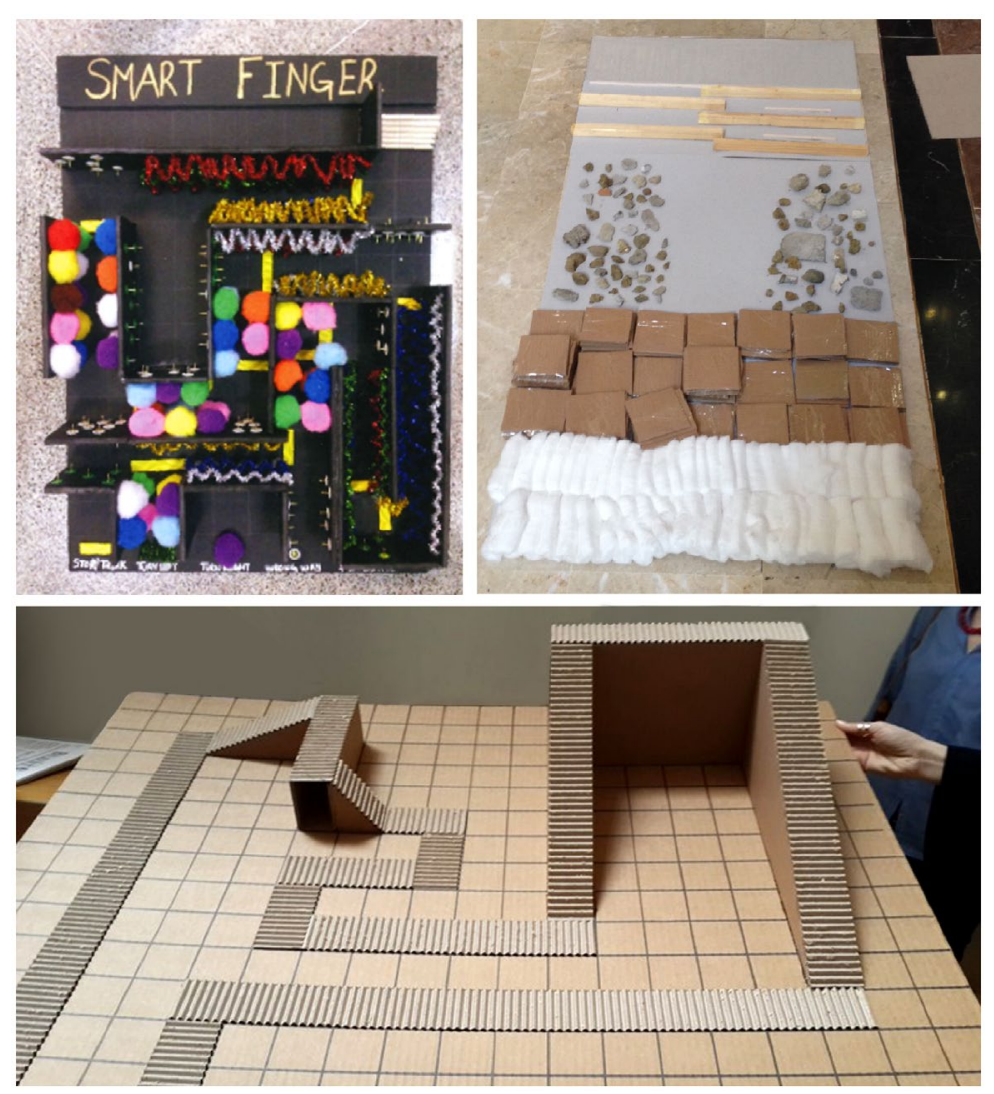

of the ground with bare feet, an experience which we would not naturally feel in interior spaces with shoes. Finally, Touch and Draw tested our sense of orientation, 3D visualization, memory, and hand-eye coordination as we tried to replicate, through drawing, the directional path of the 3D environment that we would follow by hand, again with eyes closed. The three-dimensionality, the length of paths, and the increased time in following the route made it more difficult to draw the path accurately afterwards (see Figure 5).

\section{Auditory Focus}

Several projects focused on the sense of hearing. In Dance Away, the user was able to create her own spatial experience by different movements of her body through creating sounds with the musical instruments in front and behind her. The instruments being composed of materials such as elastic bands, rice filling, etc., there was opportunity to create different sound effects by various movements (see Figure 6).

A project that totally depended on auditory capability was Sound Labyrinth, where the blindfolded user would find the end of the labyrinth by only following the similar sounds vibrating through the strings which were attached with different tensile properties. Thus, the

\section{Figure 5.}

Smart Finger, Under Your Feet, and Touch and Draw: we experience the tactile environment with our fingers, feet, and hands. 


\section{Figure 6.}

Dance Away, Sound

Labyrinth, and Sense-Mask: we explore our environment with an auditory focus.
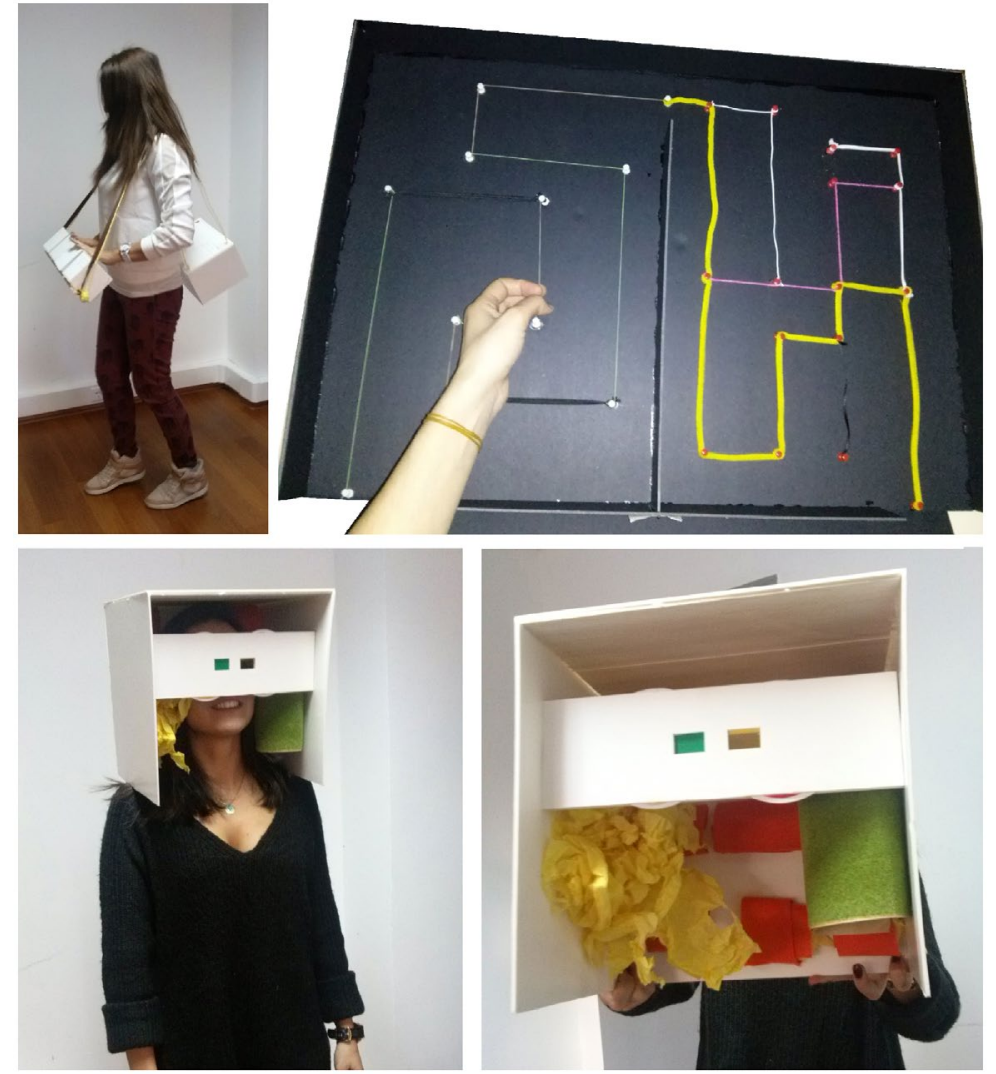

hand/fingers would change direction depending only on the sound effects of the strings (see Figure 6).

Another way of exploring space with visual, tactile, and acoustical variations was by Sense-Mask, which was composed of different materials inside. While the user felt the distinct textures on the sides and back of the head, he would also be isolated from the exterior audibly. In that respect, the acoustical properties of the materials inside the mask, covering the ears, revealed themselves in the silenced experience of space. Meanwhile, the user would have a coloured vision of the surroundings by modifying the glasses in front of her eyes, made up of yellow, blue, and red colours. Naturally, having the same or different colours radically changed the visual impact (see Figure 6).

\section{Visual Focus}

Many of the projects explored the extents of our sense of vision. They often aimed to create alternative and novel ways to see the world, such as the openings from the Crawl Space or the coloured vision of SenseMask, as previously explained. On the other hand, The Pyramid invited us to visualize and draw the 3D solid shape inside the pyramid, after only looking at the project for less than 10 seconds (see Figure 7). The 

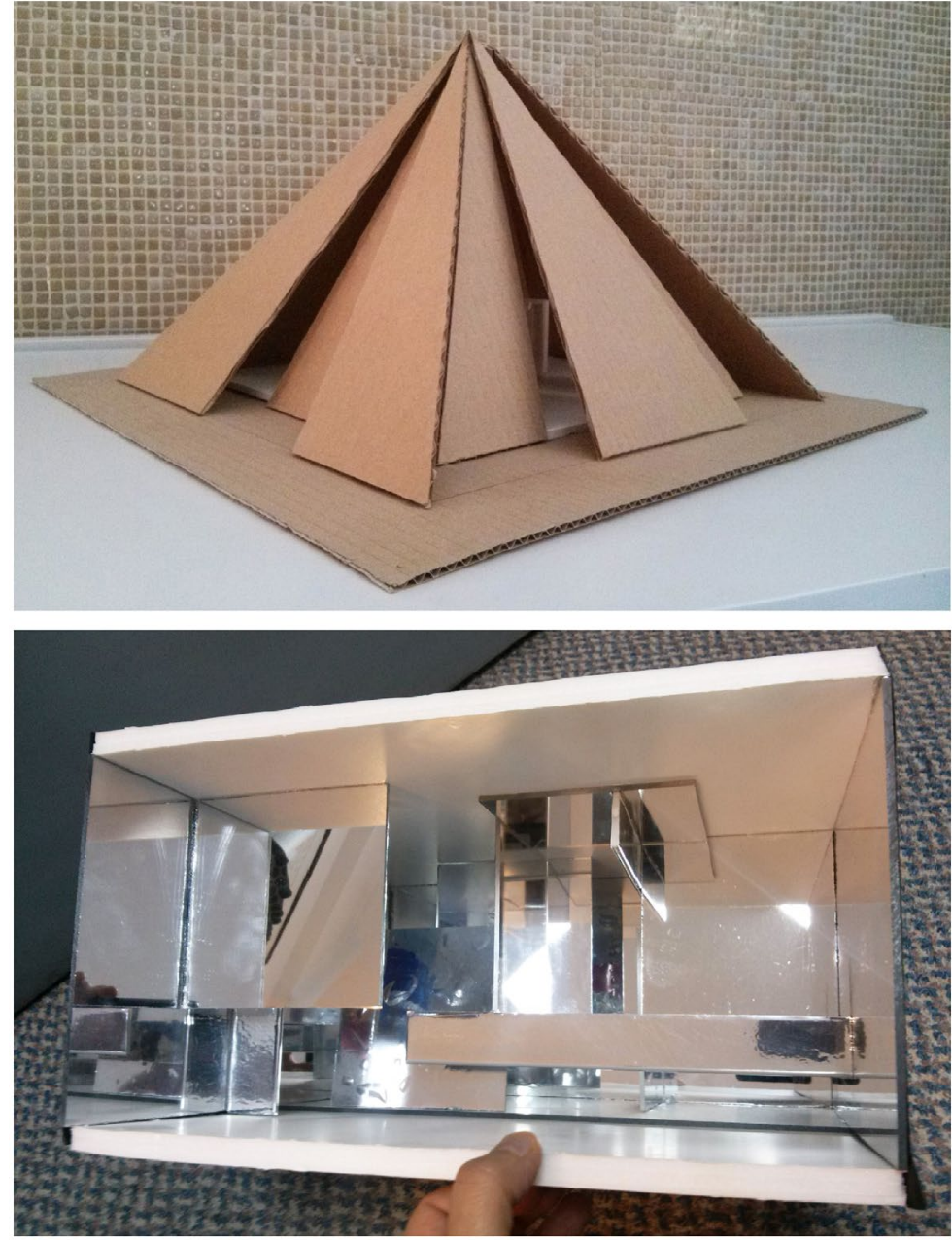

difficulty lay in the complexity of the solid form inside, the three-dimensional layering of the pyramid walls, and the lack of adequate openings to view inside.

Inception (the name inspired by the film of the same name) was designed by students as a game in which you would guess how many coloured 'cubes' (red, yellow, green, and blue) were hidden in the maze of mirrored reflection (see Figure 7). Due to the multiple layers of reflections, we had to have increased attention and awareness. Surprisingly, no one made a correct prediction. What we found out through this experience was our inability to discern the real and the reflected, as well as a natural inclination of looking towards the lower parts and the sides of the space. Since none of us looked up to the 'ceiling' of the box, we always missed the green cube. The visual experience of the project was by itself extremely appealing, and always offered us changing views as our positioning and the quality of the surroundings changed. We also became part of the picture occasionally in segmented forms.

\section{Figure 7.}

Pyramid and Inception: we explore the 3D forms and objects hidden within opaque, or reflective surfaces. 
Overall, the students enjoyed working on the projects, finding the 'right experiences', therefore learning through the process, as well as exploring those of their peers. Many of the projects, while limiting one of our senses, allowed us to find out what we could achieve with others. Through the experiences, there were just different /s or even different (positive or negative) experiences of us, as we related parts of our bodies and senses to the totality of the experience.

\section{Research on Student Feedback}

During the realization of the assignment, the students informally expressed their positive experience particularly through their participation. Thus, immediate feedback was obtained informally. Colleagues also expressed their positive views as they experienced the works which were displayed the whole semester within the department public spaces, halls, and corridors.

In addition to the analysis of the direct engagement of the projects, research was conducted with the aim of capturing students' perceptions about their learning with regard to the assignment. Student evaluations and ratings are widely applied and can be used among the array of techniques to identify learning effectiveness (Maki 2004). However, they are suggested to be administered particularly for the benefit of course progress and as research informing practice, rather than as a single source for institutional policies and decision-making (Bowman and Herzog 2011; Feldman 2007; Gonyea and Miller 2011; Theall and Feldman 2007).

\section{Methods and Procedure}

For this study, research was conducted in spring 2016, with the students who had taken the HFE course the previous two years conducting the assignment. The aim was to gain insight into students' views regarding their learning and experience of the assignment on different levels.

In student evaluation surveys, researchers caution us about biases, which refer to aspects that influence the ratings but are actually not related to the teaching and learning effectiveness (National Research Council 2003). Possible biases may arise from the course characteristics (class size, subject area, etc.), the student characteristics (expected grade, academic ability, age, etc.), or the teachers' traits (teacher attractiveness, general impression, other courses taken by instructor, gender, race, etc.).

Methods to reduce possible bias of student ratings are suggested. A significant suggestion is to offer concrete, specific, clear categories to assess instruction in the survey forms, rather than vague and broad terms (Bowman 2010; Bowman and Herzog 2011; Feeley 2002). Exemplary survey questions regarding various instructional dimensions are provided (Feldman 2007). 
Research has also revealed that the risk of bias decreases as the experience level of surveyors increases, i.e. there is less bias of e.g. second- or third-year student self-report gains in comparison with freshman students (Bowman 2010; Bowman and Herzog 2011; Feeley 2002).

During the current research, the students were in their third and fourth years in the department, and had completed the HFE course within the previous two years. Therefore, during the time of the research, they had already completed their responsibilities for the course and the instructor, and were not taking any other course from the instructor.

The students were handed a survey form at the beginning of a compulsory course hour, with permission from the instructor, who is not the instructor of the HFE course. A teaching assistant handed out and collected the survey forms without the presence of any course instructor. Upon handing in the survey form, students were told that the results would only be used for educative and research purposes. They were not required to write their names.

The first five questions asked (with answers on a five-point scale) are related to the effectiveness of the assignment in various learning domains. The format of the closed-ended questions is specific enough to relate directly to the assignment experience. Moreover, they correspond to and are congruent with exemplary questions provided by Feldman (2007) regarding stimulation of interest, perceived learning outcome, and impact of instruction as well as stimulation of creativity.

The structured questions were followed by three open-ended questions investigating: what students learned, their experiences regarding project process, and also their suggestions for the assignment's development. The survey required about 15 minutes to complete. Ninetyseven students answered the survey. There were 84 (87\%) female and $13(13 \%)$ male students, ranging in age from 18 to 24.

While the number of students is suitable for descriptive statistics of structured questions, the open-ended questions allow for thematic coding that may not be expressed through structured questions alone. This way, the results can provide a chance for us to take into account the positive and challenging aspects of the assignment from the students' perspective.

\section{Findings}

According to the study's objectives, the first five questions were analysed through descriptive statistics. Table 2 provides the overview and mean of responses.

The findings reveal that students largely find the assignment successful on the issues raised regarding learning of HFE knowledge and universal design, creative skills, and creating enthusiasm for the subject. They also believe the assignment is effective as a part of the syllabus.

Data obtained from the open-ended questions were analysed with an interpretive approach and were subjected to a qualitative analysis. 
Table 2. Student feedback on 'A 3D Experience': structured survey results.

\begin{tabular}{|c|c|c|c|c|c|c|c|c|}
\hline & $\begin{array}{c}\text { Questions: Considering } \\
\text { 'A 3D Experience' exer- } \\
\text { cise ... }\end{array}$ & 1 & 2 & 3 & 4 & 5 & Mean & $S D$ \\
\hline \multicolumn{9}{|c|}{ Number of replies ( $\mathrm{N}=97$ ) } \\
\hline 1 & $\begin{array}{l}\text { The exercise was effec- } \\
\text { tive for learning about } \\
\text { humans' relationship with } \\
\text { the physical environment. }\end{array}$ & 3 & 4 & 11 & 48 & 31 & 4.0 & 0.94 \\
\hline 2 & $\begin{array}{l}\text { The exercise was effec- } \\
\text { tive for creating interest } \\
\text { in the subject of human } \\
\text { factors/inclusive design. }\end{array}$ & 4 & 5 & 8 & 41 & 39 & 4.1 & 1.03 \\
\hline 3 & $\begin{array}{l}\text { The exercise was effec- } \\
\text { tive in increasing under- } \\
\text { standing and awareness } \\
\text { about subjects of HFE } \\
\text { and inclusive design }\end{array}$ & 4 & 3 & 15 & 36 & 39 & 4.1 & 1.02 \\
\hline 4 & $\begin{array}{l}\text { The exercise was effec- } \\
\text { tive in increasing your } \\
\text { creative skills of design- } \\
\text { ing unique/different 3D } \\
\text { experiences. }\end{array}$ & 3 & 2 & 9 & 38 & 45 & 4.2 & 0.93 \\
\hline \multirow[t]{2}{*}{5} & $\begin{array}{l}\text { You suggest that this } \\
\text { assignment should be a } \\
\text { part of the HFE course } \\
\text { syllabus. }\end{array}$ & 4 & 7 & 13 & 30 & 43 & 4.1 & 1.11 \\
\hline & $1=$ Completely disagree & & & gree & & & Agree, $5=$ & Com- \\
\hline
\end{tabular}

Student comments ranged between one-two sentences and short paragraphs. They were coded according to the emergent major themes (Boyatzis 1998).

Out of those surveyed (97), 68 students provided responses to open-ended questions. In the analysis of results, the number and percentage of students that commented on emergent themes are based on the provided responses (68). Table 3 provides an overview of the emergent themes regarding the issues of inquiry.

In terms of the learning outcomes, comments revolved around three major themes. First, supporting the structured questions, students stated that the assignment encouraged them to understand and/or experience the human-environment relationship in a much better way (34 people, 50\%). While some students gave that as a general statement (10 people, 15\%), others placed emphasis on particular subjects. For example, 16 students (24\%) stressed the significance of environment-body relationship and ergonomics, commenting that they understood and learned to use the human body and proportions, human dimensions, and scale. They also explored different bodily movements, 
Table 3. Student feedback on 'A 3D Experience': emergent themes.

\begin{tabular}{ll}
\hline \multicolumn{1}{c}{ Subject of Inquiry } & \multicolumn{1}{c}{ Emergent Themes } \\
\hline 1 Learning Outcome & Knowledge regarding human- \\
& environment relation; body, senses, \\
& feelings \\
& Attitudes regarding inclusive/universal \\
& design;increased designer respon- \\
& sibility \\
& Skills regarding creativity and 3D \\
& design \\
& Experiential quality; related to real \\
& world, applying knowledge to actual \\
& situations \\
& Enjoyable, fun quality \\
& Adequate time for project develop- \\
& ment and critiques \\
& More clearly defined topic, expecta- \\
& tions, review scale \\
& Possibility to exhibit to a wider \\
& audience \\
\hline
\end{tabular}

combined activities, and bodily limitations, particularly regarding spatial requirements - such as avoiding sharp corners, adhering to specific dimensions in passageways, etc.

In addition to the environment-body relation, students emphasized learning through experiencing with the senses (13 students, 19\%). They also observed how people respond to different sensory stimuli. Moreover, probably in accordance with the different 3D products, students felt the exercise increased awareness of the effect of light, textures, and colours on them, allowing them to feel textures of surface, or material experience, as well as perceptions of forms and objects.

Students could also experience different emotions associated with the qualities of space. Four students commented on this, acknowledging that designers should be aware of how different spaces evoke a change in feelings, emotions, and experiences:

I learned that it is important for a design to permit individuals to have different emotions and experiences within a space. At times, we may need the environment to be spacious whereas at other times we may need spaces of warmth and intimacy.

Supporting the previous learning outcome, the students commented that the exercise transformed their attitudes towards inclusive design in a positive way, and enhanced their responsibility as designers to consider all people (23 people, 34\%). As such, while 14 (21\%) students stated that the exercise helped them to understand the importance of design for everyone, 10 students (15\%) particularly mentioned that 
it increased their empathic understanding towards disabled people, making them aware of difficulties encountered in the limitations of physical environment:

(On learning) This experience was really effective to understand how important it is to think about disabled people while designing. (On the experience) It was hard and I had to trust my friend while my eyes were closed. I needed some symbols to feel my way and direction. (Suggestions) It was great, I could understand the people without sight. My designs changed accordingly.

Students also emphasized that the projects largely enhanced their creative skills (16 people, 24\%). This supports the findings from the structured questions. For them, the project required high creativity, allowed brainstorming and also analytic thinking. One student noted that the project required her 'to come up with unique solutions to the problems of space design'. Moreover, with wide boundaries they had more options to demonstrate.

Regarding the project process, students mentioned that the experiential quality of the assignment was very beneficial and effective (13 people, 19\%). As one student commented: 'The real experience is as important as the project itself'. Thus, students were of the view that the interactive nature, applying theoretical knowledge to actual practice, and full-scale model-making were the projects' strengths. The project allowed students to observe how people with diverse characteristics responded to their designs, which was not possible in other projects.

Supporting the experiential nature, students also mentioned the enjoyable quality of the exercise (12 people, 18\%). Many thought that the project was fun, and increased interest in the course. While one student noted that with this project, she felt 'free', another noted that this was one of her favourite assignments in the overall curriculum. For some students the enjoyable quality coincided with the learning outcome and the experiential nature:

I believe that what we did was sort of installation design, that's why it helped us understand design in a different way. Also, it was really fun to design something like that. I have learned how to account for all the five senses through design. It was very enjoyable.

Despite the majority of positive views on learning, two students held largely negative views on the assignment. They stated that they did not learn anything, and this project would be more suitable for a basic design or art-related course, rather than HFE course. One student also stated his disappointment in putting so much effort into a product that would have 'no use in real life'. The project's difficulty in applicability and creation as well as being group work was also a problem for these students. Thus, these comments, although few, may actually represent the views of the students who responded to the structured questions 
with negative evaluations but who declined to comment on the openended questions.

With regard to suggestions, the major suggestion that revealed a drawback of the assignment was allowing adequate time for project development (6 people, 9\%). Students required a greater number of critiques (whereas only one critique was given currently) and extended stages of the project process before model-making. Some students also required clearly defined expectations (4 people, 6\%). Thus, they suggested there should be assigned topics, specific requirements regarding project scale which would allow for easier model-making, and presentation of examples of similar projects.

Students also thought allocating more exhibition time and an accessible location within the campus would allow the projects to be experienced by a wider audience (3 people, 4\%). One student thought it would be very effective to observe how disabled people encountered the projects. On the other hand, some students suggested carrying out similar assignments of an experiential nature in the HFE course and design courses.

\section{Discussion}

In evaluating strategies for teaching inclusive design, Dong (2009) and McDonagh and Thomas (2010) argue that involving real users as a part of the design process is effective in expanding students' empathic horizons. In lecture courses such as HFE that support design studios, a variety of learner-centred methods is called for, to enrich the learning process.

Included within the HFE for second-year interior design students, the assignment 'A 3D Experience' was successful since students expanded their vision about the user-environment relationship as they both created and became users of the projects they engaged with, along with other users, their peers. As such, a connected knowing enabled the dissolution of the boundaries that constructed the differences of themselves and the user (Ballard 1997). Without making the necessary distinctions of 'us', 'them', 'blind', 'disabled', or 'user' and 'designer', the project provided an empathic framework to approach the idea of inclusivity by design.

The process and design projects of 'A 3D Experience' as well as student feedback suggest that the assignment was in alignment with the cognitive and affective learning outcomes of the HFE course: increasing knowledge and awareness of HFE and providing a positive attitude towards inclusive design, as well as developing creative skills.

Besides the positive learning outcomes, student feedback revealed that the project enhanced interest in the course and was favoured in terms of the experiential and enjoyable quality. Build-to-learn was effective since students could apply theoretical knowledge to actual practice in full scale. In that respect, this study supports earlier research that encourages physical model-making in education (Altay et al. 2016; Charlesworth 2007; Konkel 2014). Students often incorpo- 
rated aspects of surprise and play, which also increased their motivation and positive views. A creative learning environment is intrinsically motivating since the student naturally engages with the process and enjoys it (Lau 2009). Moreover, the boundaries of the problem were flexible enough where students engaged in problem-finding, as well as finding solutions on their own. Thus, encouraging self-initiated learning and emphasis on students' learning on their own are suggested as an aspect for motivation (Lau 2009) and an effective instructional dimension (Feldman 2007).

Educators should be cautionary about the limitations. Whether similar projects are included as single-day workshops, within HFE courses or design courses, instructors should carefully consider and present expectations. Moreover, adequate feedback during project progress should be given. Thus the problems posed by the students strengthen the importance of clarity of objectives and requirements, as well as the nature of feedback from the teacher, as instructional dimensions (Feldman 2007). If the assignment is repeated within a curriculum, modifications and changes could be provided every year in order to provide the context for creative engagement, such as a focus on a major theme. Allowing adequate exhibition time and the possibility to be experienced by a wide audience would also be beneficial.

Schifferstein and Desmet (2008) suggest that a multisensory approach during the design process can improve the outcome in a number of ways, such as developing new functionalities and contributing to the coherency and unity of the product. Inclusion of a multitude of senses - beyond the visual which students are usually accustomed to - including bodily movement, hearing, touching, and smelling, supports this goal. This study reveals that a multisensory design process also enhances the designers' empathic understanding towards users, through the sensitization with their own sensory and bodily experience. However, as a short-term 'episodic' assignment, it is not possible to observe its effects on the cognitive and affective learning of students in the long term and whether they apply this knowledge in other areas of design practice. A multisensory approach embedded within the curriculum of interior design departments, including courses such as design studios, construction and materials, product design, etc., would ensure the incorporation of such an approach by future professionals as an integral part of their design process. Furthermore, research on the wider impact of such activities within longitudinal studies is required.

With the understanding and application of inclusivity in design, the notion of disability may shift towards capability, so that the designed environment embraces all people with different degrees of capabilities (Clarkson 2008). I believe that the shift of focus from a simulation of another person's 'disability' to an insight into the potentials and limitations of one's own/others' bodies and senses can form the basis of an 'inclusive mindset' where further learning is cultivated. When the student designers can embrace the variety of human-environment engagement and live them as their own, they have an opportunity to convert this experience into inspiring and innovative design outcomes. 


\section{Disclosure Statement}

No potential conflict of interest was reported by the author.

\section{References}

Aditomo, A., P. Goodyear, A. Bliuc, and R. Ellis. 2011. "Inquiry-Based Learning in Higher Education: Principal Forms, Educational Objectives, and Disciplinary Variations." Studies in Higher Education 38 (9): 1239-1258. doi:10.1080/03075070.2011.616584.

Altay, B. 2017. "Developing Empathy towards Older Adults in Design." Educational Gerontology 43 (4): 198-208. doi:10.1080/03601277. 2016.1273733

Altay, B., G. Ballice, E. Bengisu, S. Alkan, and E. Paykoç. 2016. "Embracing User Experience in Inclusive Design Education through Learner-Centered Instruction." International Journal of Inclusive Education 20 (11): 1123-1141. doi:10.1080/13603116.2016.1155662.

Altay, B., and H. Demirkan. 2014. "Inclusive Design: Developing Students' Knowledge and Attitude through Empathic Modeling." International Journal of Inclusive Education 18 (2): 196-217. doi:10.108 0/13603116.2013.764933.

Ballard, K. 1997. "Reaching Disability and Inclusive Education: Participation, Construction and Interpretation." International Journal of Inclusive Education 1 (3): 243-256. doi:10.1080/1360311970010302.

Bowman, N. A. 2010. "Assessing Learning and Development among Diverse College Students." New Directions for Institutional Research 2010: 53-71. doi:10.1002/ir.322.

Bowman, N. A., and S. Herzog. 2011. "Reconciling (Seemingly) Discrepant Findings: Implications for Practice and Future Research." New Directions for Institutional Research 2011: 113-120. doi:10.1002/ ir.393.

Boyatzis, R. E. 1998. Transforming Qualitative Information: Thematic Analysis and Code Development. Thousand Oaks, CA: Sage.

Burgstahler, S., and T. Doe. 2004. "Disability-Related Simulations: If, When, and How to Use Them." Review of Disability Studies 1 (2): 4-17.

Cardoso, C., and P. J. Clarkson. 2012. "Simulation in User-Centered Design: Helping Designers to Empathize with Atypical Users." Journal of Engineering Design 23 (1): 1-22. doi:10.1080/0954482 1003742650.

Cavanagh, M. 2011. 'Students' Experiences of Active Engagement through Cooperative Learning Activities in Lectures." Active Learning in Higher Education 12 (1): 23-33.

Charlesworth, C. 2007. "Student Use of Virtual and Physical Modelling in Design Development - An Experiment in 3D Design Education." The Design Journal 10 (1): 35-45. doi:10.2752/146069207789318027.

Clarkson, P. J. 2008. "Human Capability and Product Experience." In Product Experience, edited by H. N. J. Schifferstein and P. Hekkert, 165-198. San Diego: Elsevier. 
Cross, N. 1982. "Designerly Ways of Knowing." Design Studies 3 (4): 221-227. doi:10.1016/0142-694X(82)90040-0.

Deeley, S. 2010. "Service-Learning: Thinking outside the Box." Active Learning in Higher Education 11 (1): 43-53.

Dong, H. 2009. "Strategies for Teaching Inclusive Design." Journal of Engineering Design 21 (2-3): 237-251.

Elsen, C., and A. Heylighen. 2014. "Representations of Sensory Experiences in the Early Phases of Architectural Design: There is More than Meets the Eye." Journal of Design Research 12 (4): 239-259.

Feeley, T. H. 2002. "Evidence of Halo Effects in Student Evaluations of Communication Instruction." Communication Education 51 (3): 225-236.

Feldman, K. A. 2007. "Identifying Exemplary Teachers and Teaching: Evidence from Student Ratings." In The Scholarship of Teaching and Learning in Higher Education: An Evidence-Based Perspective, edited by R. P. Perry and J. C. Smart, 93-143. Dordrecht: Springer.

French, S. 1992. "Simulation Exercises in Disability Awareness Training: A Critique." Disability, Handicap and Society 7 (3): 257-266. doi:10.1080/02674649266780261.

Gonyea, R. M., and A. Miller. 2011. "Clearing the AIR about Use of Self-Reported Gains in Institutional Research." New Directions for Institutional Research 2011: 99-111. doi:10.1002/ir.392.

Hitchcock, D., and A. Taylor. 2003. "Simulation for Inclusion...True User-Centered Design?" In Proceedings of Include 2003, edited by J. Bound, and R. Coleman, 105-110. London: Royal College of Art, The Helen Hamlyn Research Center.

Kolb, D. 1984. Experiential Learning: Experience as the Source of Learning and Development. Englewood Cliffs, NJ: Prenctice Hall.

Konkel, M. 2014. "Build-to-Learn: An Examination of Pedagogical Practices in Interior Design Education." Journal of Interior Design 39 (2): 1-16.

Kouprie, M., and F. S. Visser. 2009. "A Framework for Empathy in Design: Stepping into and out of User's Life." Journal of Engineering Design 20 (5): 437-448. doi:10.1080/09544820902875033.

Lau, K.W. 2009. "Creativity Training in Higher Design Education." The Design Journal 12 (2): 153-169. doi:10.2752/175630609X433111.

Lee, N. 2009. "Project Methods as a Vehicle for Learning in Undergraduate Design Education: A Typology." Design Studies 30 (5): 541-560. doi:10.1016/j.destud.2009.03.002.

Lizzio, A. J., and K. L. Wilson. 2004. "First-Year Students' Perceptions of Capability." Studies in Higher Education 29 (1): 109-128. doi:10. 1080/1234567032000164903.

Maki, P.L. 2004. Assessing for Learning. Sterling, VA: Stylus.

McDonagh, D., and J. Thomas. 2010. "Disability + Relevant Design: Empathic Design Strategies Supporting More Effective New Product Design Outcomes." The Design Journal 13 (2): 180-198. doi:10.275 2/175470710X12735884220899. 
McGinley, C., and H. Dong. 2011. "Designing with Information and Empathy: Delivering Human Information to Designers." The Design Journal 14 (2): 187-206. doi:10.2752/175630611X 12984592780005.

Morrow, R., ed. 2002. Centre for Education and the Built Environment. Building and Sustaining a Learning Environment for Inclusive Design: A Framework for Teaching Inclusive Design within Built Environment Courses in the UK. Final Report of the Special Interest Group in Inclusive Design for Centre for Education in the Built Environment. UK: Center of Education. https://cebe.cf.ac.uk/learning/sig/inclusive/full_report.pdf.

National Research Council. 2003. Evaluating and Improving Undergraduate Teaching in Science, Technology, Engineering, and Mathematics, edited by M. A. Fox and N. Hackerman. Washington, DC: The National Academies Press. http://www.nap.edu/catalog/10024. html.

Nickpour, F., and H. Dong. 2011. "Designing Anthropometrics! Requirements Capture for Physical Ergonomic Data for Designers." The Design Journal 14 (1): 92-111. doi:10.2752/175630610X128773 85838849.

Nicolle, C., and M. Maguire. 2003. "Empathic Modeling in Teaching Design for All." In Universal Access in $\mathrm{HCl}$, Inclusive Design in the Information Society-Volume 4 of the Proceedings of the 2nd International Conference on the Universal Access in Numan-Computer Interaction, June 22-27. Crete, Greece, edited by C. Stephanidis, 143-147. Mahwah, NJ: Lawrence Erlbaum.

Peel, D., and P. J. Posas. 2009. "Promoting Disability Equality and Inclusive Learning in Planning Education." Innovations in Education and Teaching International 46 (2): 227-235.

Postma, C. E., E. Zwartkruis-Pelgrim, E. Daemen, and J. Du. 2012. "Challenges of Doing Empathic Design: Experiences from Industry." International Journal of Design 6 (1): 59-70.

Schifferstein, H. N. J., and P. M. A. Desmet. 2008. "Tools Facilitating Multi-Sensory Product Design.” The Design Journal 11 (2): 137-158. doi:10.2752/175630608X329226.

Schifferstein, H. N. J., and C. Spence. 2008. "Multisensory Product Experience." Product Experience, edited by H. N. J. Schifferstein and P. Hekkert, 133-161. San Diego: Elsevier.

Stein, S.J., G. Isaacs, and T. Andrews. 2006. "Incorporating Authentic Learning Experiences within a University Course." Studies in Higher Education 29 (2): 239-258.

Suri, J. F. 2001. "The Next 50 Years: Future Challenges and Opportunities for Empathy in Our Science." Ergonomics 44 (14): 1279-1289.

Theall, M., and K. A. Feldman. 2007. "Commentary and Update on Feldman's (1997) 'Identifying Exemplary Teachers and Teaching: Evidence from Student Ratings'." In The Scholarship of Teaching and Learning in Higher Education: An Evidence-Based Perspective, edited by R. P. Perry and J. C. Smart, 130-143. Dordrecht: Springer. 
Turner, P., and S. Turner. 2011. "Is Stereotyping Inevitable When Designing with Personas?" Design Studies 32 (1): 30-44. doi:10.1016/j. destud.2010.06.002.

Wastiels, L., H. N. J. Schifferstein, I. Wouters, and A. Heylighen. 2013. "Touching Materials Visually: About the Dominance of Vision in Building Material Assessment." International Journal of Design 7 (2): 31-41.

Wijk, M. 2001. "The Dutch Struggle for Accessibility Awareness." Universal Design Handbook, edited by W. F. E. Preiser and E. Ostroff, 28.1-28.17. New York: McGraw Hill.

\section{Biography}

Burçak Altay is currently assistant professor of practice in the Interior Architecture and Environmental Design Department at Bilkent University, Ankara, where she teaches Design Studio and Human Factors courses. She earned her BArch from Middle East Technical University, MFA and PhD from Bilkent University. She previously worked as a programmer, designer, and technical coordinator at Skidmore, Owings \& Merrill architectural firm in New York, USA. Her research areas include inclusive design, empathic design education, architectural ethics, professional practice, and design creativity.

\section{Address for Correspondence}

Burçak Altay, Department of Interior Architecture and Environmental Design, Bilkent University, Ankara, Turkey.

Email: burcak@bilkent.edu.tr 